\title{
PENYULUHAN GEMAR MENABUNG UNTUK MASA DEPAN YANG CERAH DI SMP NEGERI KELURAHAN HARAPAN JAYA - KOTA BEKASI
}

\author{
Bintang Narpati ${ }^{1}$, Indra Lubis ${ }^{2}$, Kardinah Indriana Meutia ${ }^{3}$ \\ Universitas Bhayangkara Jakarta Raya ${ }^{1,2,3}$ \\ E-Mail : bintang.narpati@dsn.ubharajaya.ac.id¹, indra.lubis@dsn.ubharajaya.ac.id², \\ kardinah.meutia@dsn.ubharajaya.ac.id ${ }^{3}$
}

\author{
Article History: \\ Received: 09-02-2021 \\ Revised: 15-02-2021 \\ Accepted: 20-02-2021
}

\section{Keywords:}

Save; Prosperous Life; Future; Savings. $\begin{array}{lr}\text { Kata Kunci: } & \\ \text { Menabung; } & \text { Kehidupan } \\ \text { Sejahtera; } & \text { Masa }\end{array}$

Tabungan.

\begin{abstract}
Saving is the first step in facing a better future for a prosperous life. To achieve this goal, from an early age, it is better if children who are studying in elementary school or kindergarten are taught to like to save money. You don't need a lot of money to save in the savings place, but only enough to set it aside from the smallest nominal, for example Rp. 500, - (five hundred rupiah) first because according to research (Furnham, 1999) that more than $80 \%$ of children claim their parents will not give them extra money if they spend it all. This requires saving activities for children. Why saving for early childhood does not require large funds, in this case, the main point of saving is to foster a feeling of being fond of saving since childhood. Why is it done in early childhood? because by doing these habits will foster adult habits later to always save in any circumstances. The form of activities carried out at Community Service (PKM) is in the form of counseling to the children of SMPN 5 kota Bekasi City for grades 1,2 and 3. The counseling is in the form of an appeal to these children to set aside money if they are given pocket money by their parents. This is done is by providing an example of how to save by carrying a piggy bank that is easy to buy in bookstores or others. Some are made of plastic, cans or fabric. In essence, saving is by setting aside "unused" money to be saved and reused when "needed". This training is an activity of Community Service (PKM) for the residents of Harapan Jaya kota Bekasi Village. The plan for this activity to be carried out in mid-November 2020 at SMPN 5 kota Bekasi which is still in the Bekasi city area.
\end{abstract}

Abstrak: Menabung merupakan langkah awal dalam menghadapi masa depan yang lebih baik untuk kehidupan sejahtera. Untuk mencapai tujuan tersebut, dari usia sejak dini, sebaiknya diajarkan bagi anak - anak yang sedang belajar dibangku sekolah dasar ataupun masih taman kanak - kanak untuk dibiasakan gemar menabung. Tidak perlu uang yang cukup banyak untuk menyimpan di tempat tabungan tersebut tetapi hanya cukup untuk menyisihkannya dari nominal terkecil misalnya Rp. 500,- (lima ratus rupiah) dulu. Untuk itu diperlukan kegiatan menabung bagi anak - anak. Mengapa menabung bagi anak - anak usia dini tidak perlu dana yang besar, dalam hal ini adalah ini dari pokok menabung adalah menumbuhkan rasa gemar menabung sejak kecil. Mengapa hal itu dilakukan pada anak - anak usia dini ? karena dengan melakukan kebiasaan tersebut akan memupuk kebiasaan dewasa nanti untuk selalu menabung dalam keadaan apapun. Bentuk kegiatan yang dilakukan pada Pengabdian Kepada Masyarakat (PKM) ini adalah berupa penyuluhan kepada anak - anak SMPN 5 Kota Bekasi kelas 1 , 2 dan 3. Penyuluhan berupa himbauan kepada anak - anak tersebut untuk menyisihkan uang apabila diberikan uang jajan oleh orang tuanya. Hal yang dilakukan adalah dengan memberikan contoh cara menabung dengan membawa celengan yang mudah dibeli di toko - toko buku ataupun lainnya. Ada yang terbuat dari plastik, kaleng ataupun bahan kain. Pada intinya adalah menabung tersebut dengan menyisihkan uang yang "tidak terpakai" untuk ditabung dan digunakan kembali pada saat "dibutuhkan". Pelatihan ini merupakan kegiatan dari Pengabdian Kepada Masyarakat (PKM) terhadap warga kelurahan Harapan Jaya kota Bekasi. Rencananya kegiatan ini telah dilaksanakan pada pertengahan bulan November 2020 di SMPN 5 kota Bekasi yang masih berada dalam wilayah bekasi kota. 


\section{Pendahuluan}

Memiliki sesuatu yang diimpikan oleh seseorang merupakan hal yang wajar dalam suatu kehidupan. Rumah, kendaraan, pendidikan tinggi, wisata dan lain-lain adalah contoh dari salah satu keinginan dari seseorang untuk mendapatkannya. Selain kebahagian batin tentunya secara rohaniah pun seseorang akan merasakan kepuasannya. Umumnya seseorang melakukan suatu kegiatan atau aktivitas besar untuk mendapatkan barang yang diimpikannya itu. Seperti keinginan bekerja di salah satu perusahaan besar dengan penghasilan yang besar pula. Mereka berlomba-lomba dalam meningkatkan baik dari pengetahuan maupun ketrampilannya namun tidak sedikit pula orang dalam hal ini melakukan tindakan yang tidak terpuji untuk mendapatkannya. Hal yang tersulit dalam menjalani kehidupan adalah mengenai ketekunan dalam menabung. Menabung dapat menjadi hal yang sulit bila individu tidak melakukannya dengan sungguh-sungguh, bahkan terkadang menjadi tidak berhasil [1]. Dalam hal ini diperlukan pembelajaran yang bermutu dengan bimbingan guru yang professional pada tingkatannya. Menurut [2] menyatakan bahwa pembelajaran yang dilaksanakan secara bermutu akan mengeluarkan lulusan yang berkualitas, namun untuk mendapatkan pembelajaran yang bermutu tersebut membutuhkan guru yang professional, sehingga dihasilkan lulusan yang memiliki kompetensi profesional sesuai dengan perubahan jaman.

Lulus dari perguruan tinggi, bagi seseorang ada yang ingin melanjutkan ke jenjang yang lebih tinggi lagi ataupun langsung bekerja. Dalam melanjutkan ke jenjang yang lebih tinggi, tentunya dibutuhkan biaya yang tidak sedikit pula. Bila seseorang memiliki tabungan yang menyediakan untuk kegiatan melanjutkan studi lagi tentu tidak masalah namun bila tidak memiliki uang atau tabungan yang cukup maka akan menjadi masalah bahkan tidak dapat melanjutkan setudi lagi. Menurut penelitian [3] bahwa lebih dari $80 \%$ anak-anak mengklaim orang tua mereka tidak akan memberi mereka uang tambahan jika mereka menghabiskan semuanya.

Setelah bekerja, tentunya seseoang ingin melanjutkan ke jenjang pernikahan, untuk pernikahanpun diperlukan modal yang tidak sedikit. Bagi seseorang yang memiliki penghasilan di atas rata-rata perbulan atau lebih besar tentu tidak menjadi masalah untuk melansgusngkan resepsi pernikahan namun bila dana yang dimiliki terbatas maka seseorang akan mengalami kesulitan dalam resepsi pernikahan dan lainnya. Kebutuhan dana tidak terbatas pada kelanjutan studi dan pernikahan saja namun lebih luas lagi yaitu untuk mewujudkan keinginan lainnya seperti naik haji, umroh, wisata dan kebutuhan lainnya. Pengeluaran kebutuhan sehari-hari menjadi hal yang tidak terelakkan atau harus dilakukan dalam manajemen finansial individu ataupun keluarga [4].

Merancang masa depan yang cerah diperlukan dengan istilah perencanaan keungan atau financial planning. Banyak sekali workshop ataupun seminar-seminar 
yang menyuguhkan tema financial planning. Namun dibalik semua itu adalah tersedianya dana yang tersimpan untuk dapat digunakan pada saat yang tepat. Mungkin akan digunakan dalam 5 tahun, 10 tahun atau bahkan 20 tahun mendatang. Untuk itulah bagi seseorang yang belum paham mengenai financial planning, biasanya akan mengikuti seminar ataupun workshop ini. "Menabung dapat menangkal kegelisahan kematian dan merupakan penyangga yang lebih efektif daripada membelanjakan uang" menurut penelitian [5].

Memenuhi kebutuhan di saat waktu yang genting memerlukan persiapan atau cadangan yang telah dipersiapkan jauh hari. Seseorang tidak bisa secara langsung mengeksekusi kegiatan atau tranksaksi yagn diinginkan secara langsumg tanpa perencanaan sebelumnya. Sebagai contoh yang sebelumnya adalah melanjutkan studi ataupun melangsungkan pernikahan membutuhkan biaya yang tidak sedikit. Untuk itu perlunya penanaman atau pembentukan karakter gemar menabung sejak usia dini. Mengantisipasi kebutuhan yang tidak diduga ataupun untuk kegiatan yang memerlukan dana besar maka diperlukan menabung dana sesuai keinginannya di masa datang. Dalam keadaan darurat, hal yang tidak dapat dihindari oleh siapapun adalah sakit yang memerlukan dana yang tidak sedikit dalam menjalani perawatan, pada keadaan tersebut beberapa individu melakukan cara yang paling mudah yaitu dengan berhutang [6]. Untuk itu jika ada niat ingin menabung namun masih memiliki banyak hutang, sebaiknya dimulai dengan melunasi hutang-hutang terebut terlebih dahulu untuk membebaskan seseorang dari lilitan hutang dan bunganya [7].

Menabung bagi usia dini tidak perlu datang ke bank ataupun ke tempat lembahga keuangan lainnya. Namun cukup untuk tahap awal adalah dengan memberikan seorang anak berupa celengan. Disinilah dibituhkan peran orang tua dalam membimbing anak di usia dini untuk memberikan pengetahuan mengenai betapa pentingnya menabung. Menurut penelitian yang dilakukan oleh [8] bahwa "faktorfaktor yang mungkin menjelaskan tingkat gemar menabung pada anak, dua dari tiga variabel, yaitu, pentingnya persepsi sikap orang tua dan teman sebaya terhadap penghematan uang dan akses anak terhadap uang, memainkan peran penting dalam menentukan tingkat anak dalam gemar menabung."

Pembentukan jiwa hemat dan gemar menabung dilakukan melalui penyuluhan ini. Pembentukan jiwa karakter hemat dan gemar menabung akan lebih mengena pada anak - anak usia dini dibandingkan dengan remaja bahkan orang dewasa karena pada umumnya remaja dan orang dewasa sudah memiliki kebutuhannya masing - masing. Menurut penelitian [9] bahwa "memiliki uang saku memengaruhi pengeluaran makanan dan pakaian remaja secara negatif. Dibandingkan dengan remaja wanita, pria lebih sedikit menabung dan menghabiskan lebih sedikit untuk pakaian dan barangbarang perawatan pribadi." Hal ini dapat dilakukan kepada remaja dan orang dewassa melalui pelatihan secara mendalam mengenai kesadaran dan manfaat dari menabung walaupun jangka waktu menabung dapat dikatakan tidak banyak dibandingkan ketika 
waktu masih anak - anak. Menurut penelitian [10], bahwa "dampak dari sosialisasi keuangan kepada orang tua atau dewasa adalah orang tua akan sadar pada usia lanjut cenderung untuk menabung". Melalui penyuluhan ini, diharapkan murid - murid sekolah dasar memiliki jiwa hemat dan gemar menabung serta memiliki masa depan yang cerah.

Tujuan kegiatan pelaksanaan kegiatan ini adalah :

1. Memberikan pengetahuan mengenai pentingnya menabung.

2. Memberikan pelatihan mengenai cara menabung.

3. Memberikan motivasi bagi murid-murid sekolah menengah untuk gemar menabung.

4. Membentuk karakter jiwa murid-murid sekolah dasar untuk hidup hemat dan gemar menabung.

5. Membentuk kebiasaan dari murid-murid sekolah dasar untuk meyisihkan uang yang didapat untuk ditabung.

6. Memberikan pengetahuan mengenai manfaat dari menabung dikemudian hari.

Sedangkan manfaat dari kegiatan ini adalah:

1. Peserta didik dapat memahami arti pentingnya menabung.

2. Peserta didik dapat merealisasikan kegiatan menabung dalam kehidupan seharihari.

3. Melalui pelatihan ini dapat menstimulus pemikiran siswa/i sekolah dasar untuk hidup hemat dan gemar menabung.

4. Membiasakan menabung dari usia dini hingga dewasa nanti.

5. Bagi mitra SMPN 5 Kota Bekasi ini diharapkan penyuluhan ini dapat membantu dalam pemberian materi pendidikan karakter membentuk hidup hemat.

6. Melalui penyuluhan ini menunjukkan bahwa pihak universitas peduli terhadap masyarakat sekitar dalam melaksanakan Tri Dharma Perguruan Tinggi.

\section{Metode}

Pelaksanaan kegiatan Pengabdian Kepada Masyarakat (PKM) berupa penyuluhan mengenai kebiasaan untuk gemar menabung telah dilaksanakan bulan Nopember 2020 dengan peserta didik adalah para siswa SMPN 5 Kota Bekasi kelas 7 dan para guru. Metode kegiatan pengabdian kepada masyarakat yang telah dilakukan ini menggunakan metode ceramah dan tanya jawab antara peserta dengan narasumber. Metode ceramah digunakan menyampaikan pengetahuan secara umum tentang materi makna pentingnya untuk menabung selain berguna bagi diri sendiri dan juga bagi orang tua. 


\section{Hasil dan Pembahasan}

Kegiatan Pengabdian Kepada Masyarakat (PKM) berupa penyuluhan gemar menabung untuk masa depan yang cerah ini dilakukan pertama kali di SMPN 5 Kota Bekasi. Melalui tahap awal ini dapat dilihat perkembangan kelanjutan dari kegiatan ini untuk dipertimbangkan dalam mitra binaan pada Sekolah Menengah. SMPN 5 Kota Bekasi ini memiliki murid kurang lebih 1.300 siswa dari kelas 7,8 dan 9.

Objek yang dijadikan pengabdian kepada masyarakat ini adalah kelas 7 yang mulai beranjak usia remaja dimana pembinaan masih dapat dilakukan melalui berbagai macam bentuk penyampaiannya. Adapun untuk guru yang dijadikan objek untuk kegiatan ini adalah agar dapat menjadi Train of Trainer (ToT) kepada para siswa lainnya yang tidak diikutsertakan pada kegiatan ini. Hal ini dapat disampaikan saat para guru memberikan mata pelajaran kepada para siswa dengan memanfaatkan waktu yang luang.

Pada intinya, penyuluhan gemar menabung ini adalah untuk membiasakan siswa sekolah menengah pertama ini untuk gemar menabung dan dapat mandiri dan membantu orang lain. Adapun target pasca penyuluhan ini adalah :

1. Para siswa dapat merealisasikan materi yang telah didapat pada saat penyuluhan untuk dipraktekan di rumah.

2. Para siswa dapat menyisihkan uang yang telah diberikan oleh orang tuanya untuk dapat ditabung.

3. Para siswa terbiasa melakukan penyimpanan uang tanpa harus diingatkan kembali oleh orang tuanya atau secara langsung telah terbentuk pola kegiatan gemar menabung.

4. Para siswa dapat bertanya kepada orang tua di rumah untuk diajarkan bagiaman cara menyisihkan uang untuk di tabung.

5. Para siswa dapat menggunakan uang yang telah ditabung untuk keperluan yang sangat penting dengan didampingi oleh orang tua.

6. Menerbitkan artikel ini dalam jurnal nasional bereputasi.

7. Menerbitkan buku mengenai pentingnya menabung saat pandemic covid-19.

\section{Diskusi}

Pelaksanaan Kegiatan Pengabdian Kepada Masyarakat (PKM) ini dilakukan untuk memberikan pengetahuan dan pemahaman mengenai arti pentingnya menabung sejak usia dini dengan tujuan agar dapat memberikan masa depan yang cerah. Kegiatan ini melibatkan para guru dan beberapa siswa kelas 7 di SMPN 5 Kota Bekasi.

Tujuan kegiatan ini adalah untuk memberikan pengetahuan mengenai bagaimana cara menabung dengan tidak mengganggu keperluan sehari - hari, memberikan motivasi untuk gemar menabung, membentuk karakter jiwa untuk hidup 
hemat dan gemar menabung, membentuk kebiasaan yang baik untuk meyisihkan uang yang didapat baik dari orang tua atau sumber lainnya untuk ditabung dan memberikan pengetahuan mengenai manfaat dari menabung dikemudian hari.

Manfaat kegiatan ini adalah para siswa dapat memahami arti pentingnya menabung dan dapat merealisasikan kegiatan menabung dalam kehidupan sehari hari, melalui pelatihan ini dapat menstimulus pemikiran siswa sekolah menengah untuk hidup hemat dan gemar menabung dan membiasakan menabung dari usia dini hingga dewasa nanti. dan bagi mitra SMPN 5 Kota Bekasi ini diharapkan penyuluhan ini dapat membantu dalam pemberian materi pendidikan karakter membentuk hidup hemat.

\section{Kesimpulan}

Untuk mendukung kegiatan pelaksanaan kegiatan masyarakat ini sebaiknya :

1. Dilanjutkan dengan materi parenting bagi orang tua murid untuk lebih memberikan peranan kepada putra putrinya dalam rangka hidup hemat dan gemar menabug.

2. Adanya dukungan dari pihak guru-guru di sekolah dalam memonitor perkembangan para siswa dalam menabung di celengan dengan menyarankan para siswa unutk membawa celengan dan menyimpannya disekolah.

3. Membuat spanduk ataupun banner disalah satu sudut ruangan tentang pentingnya menabung agar para siswa tetap konsisten dalam menabung.

\section{Daftar Referensi}

[1] H. Merdeka, "Cara Menabung yang Tepat Agar Tak Jatuh Miskin di Masa Depan," Merdeka.com, Jakarta, 2020.

[2] S. Rizal, M. Munawir, U. S. Sulistyawati, and M. Jamil, "Pengembangan Kemampuan Diri Melalui Test Minat Bakat Siswa-Siswi SMK," Ethos, vol. 8 No.2, p. 301, 2020, [Online].

Available: https://ejournal.unisba.ac.id/index.php/ethos/article/view/5927.

[3] A. Furnham, "The saving and spending habits of young people," J. Econ. Psychol., 1999, doi: 10.1016/S0167-4870(99)00030-6.

[4] Cermati.com, “8 Tips Mengatur Gaji Untuk Masa Depan Cerah," Tips Keuang., 2015, [Online]. Available: https://www.cermati.com/artikel/8-tips-mengatur-gajiuntuk-masa-depan-cerah.

[5] T. Zaleskiewicz, A. Gasiorowska, and P. Kesebir, "Saving can save from death anxiety: Mortality salience and financial decision-making," PLoS One, 2013, doi: 10.1371/journal.pone.0079407.

[6] N. Ramadhani, "5 Manfaat Menabung Untuk Masa Depan," Akseleran, 2018. https://www.akseleran.co.id/blog/manfaat-menabung/ (accessed Oct. 17, 2018). 
Jurnal Pengabdian Masyarakat Nusantara

[7] V. M. Putri, “7 Tips Menabung untuk Masa Depan yang Cerah,” detik.com, Jakarta, p. lifestyle wolipop.

[8] T. Te'eni-Harari, "Financial literacy among children: the role of involvement in saving money," Young Consum., 2016, doi: 10.1108/YC-01-2016-00579.

[9] M. J. Alhabeeb, "Teenagers' money, discretionary spending and saving," J. Financ. Couns. Plan., 1996.

[10] A. Bucciol and M. Veronesi, "Teaching children to save: What is the best strategy for lifetime savings?," J. Econ. Psychol., 2014, doi: 10.1016/j.joep.2014.07.003. 